\title{
A cost-benefit analysis of smoking cessation prescription coverage from a US payer perspective
}

This article was published in the following Dove Press journal: ClinicoEconomics and Outcomes Research

\author{
Christine L Baker' \\ Yao Ding ${ }^{2}$ \\ Cheryl P Ferrufino ${ }^{2}$ \\ Stacey Kowal ${ }^{2}$ \\ Jenen $\operatorname{Tan}^{3}$ \\ Prasun Subedi' \\ 'Patient \& Health Impact, Pfizer, \\ Inc, New York, NY, USA; ${ }^{2}$ Health \\ Economics \& Outcomes Research, \\ Real World Evidence Solutions, \\ IQVIA, Fairfax, VA, USA; '3QVIA, San \\ Francisco, CA, USA
}

Introduction: Smoking drives substantial direct health care spending, comprising 8.7\% (\$168 billion) of annual United States aggregated spending. Smoking cessation (SC) prescription use is an effective strategy to improve health outcomes, increase quit rates, and reduce economic burden. However, patient out-of-pocket costs may limit the use. Health care payers play a vital role in driving use through formulary decisions and copayment policies but must consider both the near-term financial investment as well as downstream effects of increased coverage on health care budgets. This study estimates the return on investment (ROI) of providing Affordable Care Act (ACA)-recommended prescription SC coverage.

Methods: A cost-benefit analysis (CBA) estimates the ROI of providing prescription SC coverage, based on pharmacy costs and savings from smoking-attributable medical expenditures among Medicare, Medicaid, and commercial plan enrollees over 10 years. The CBA incorporated national-level population demographics, smoking prevalence estimates, proportion of smokers attempting to quit, and the utilization of SC products. A five-state Markov chain model simulated patterns of quit attempts, relapse, and cessation assuming two quit attempts per year, no patient cost-sharing, and $25.4 \%$ utilization of prescription SC aids. Results include number of quitters, annual pharmacy and smoking-attributable medical costs, and ROI.

Results: After initial investment in SC treatment, smoking-attributable medical benefits accrue over time, generating a positive ROI by year 4 for commercial (11.3\%) and Medicaid (78.4\%) plans and by year 3 for Medicare (30.6\%). Over 10 years, an average return of $\$ 1.18, \$ 2.50$, and \$3.22 savings per dollar spent on SC prescriptions for commercial, Medicaid, and Medicare plans, respectively, may be realized.

Discussion: Given the proven efficacy of SC pharmacotherapy, near-term investments in supporting ACA-recommended SC coverage translate into a positive ROI. As smoking is a leading cause of morbidity and mortality, increased access to prescription SC medications may improve health outcomes and reduce smoking-attributable costs to payers over time.

Keywords: cost-benefit analysis, smoking cessation prescription coverage, smoking-attributable medical cost, return on investment

\section{Introduction}

According to the Centers for Disease Control and Prevention (CDC), about 15.1\% of US adults (36.5 million) were current smokers in $2015 .{ }^{1}$ Despite considerable progress in smoking cessation (SC) efforts over time, smoking remains the leading preventable cause of disease, disability, and death in the USA. Smoking (and exposure to secondhand smoke) may lead to a wide range of diseases such as lung cancer, coronary heart diseases, and pulmonary diseases, and is linked to about one of every five premature
Health Economics \& Outcomes Research, Real World Evidence Solutions, IQVIA, 8280 Willow Oaks Corporate Drive, Suite 775, Fairfax, VA 2203I, USA

Tel +l 4842432017

Email yao.ding@iqvia.com 
deaths in the USA each year. ${ }^{2}$ In addition to the clinical consequences, smoking also has a major economic impact. Smoking continues to be a major contributor to direct health care spending in the USA. Across all US payers, cigarette smoking was associated with $8.7 \%$ ( $\$ 168$ billion) of annual aggregated health care spending in $2010 .{ }^{3}$ More than $60 \%$ of the smoking-attributable spending was paid by public programs, including $\$ 45$ billion by Medicare (9.6\%), $\$ 40$ billion by Medicaid (15.2\%), and $\$ 24$ billion by other federal health care programs $(32.8 \%) .{ }^{3}$ Moreover, the burden of smoking goes beyond direct medical costs to impact society more holistically, with an estimated $\$ 107.6$ billion indirect cost due to loss of productivity in the USA annually. ${ }^{2}$

$\mathrm{SC}$ is one of the most effective strategies to improve health outcomes and reduce health care burden. ${ }^{4-6}$ A recent USA study concluded that if smokers quit before experiencing any symptoms of smoking-related disease, $\sim 70 \%$ of their excess medical care costs could be avoided. ${ }^{7}$ A majority of current smokers are interested in quitting and attempting to quit, for example, in $2015,68.0 \%$ of current smokers were interested in quitting and $55.4 \%$ made a quit attempt in the previous year. However, only $29.0 \%$ of those attempting to quit used $\mathrm{SC}$ medication therapies (including both prescriptions and over-the-counter [OTC] drugs) as part of their quit attempt. ${ }^{8}$ This relatively low utilization of SC therapies limits the success of these quit attempts, as only $5 \%$ of smokers who attempt to quit smoking unaided are successful on average. ${ }^{9}$ The CDC notes that reducing out-of-pocket (OOP) costs for $\mathrm{SC}$ treatments effectively increases patient access to these medications and, therefore, the number of tobacco users who successfully quit. ${ }^{10}$ Recent policy initiatives, for example, the Affordable Care Act (ACA) also recommends that group health plans and health insurance issuers provide coverage without patient cost-sharing for 1) screening of all patients for tobacco use; 2) at least two tobacco-cessation attempts per year for enrollees who use tobacco products, with coverage for each quit attempt including four tobacco-cessation counseling sessions, each for a minimum of 10 minutes, including telephone, group, and individual counseling; and 3 ) coverage for any US Food and Drug Administration (FDA)-approved tobacco-cessation medications (whether prescription or OTC) for a 90-day treatment regimen when prescribed by a health care provider. ${ }^{11}$ Patient access to SC therapies, although improving because of these recommendations, remains below recommended levels. ${ }^{2,10}$ A 2015 study found that only $18 \%$ of publicly available formularies for state and federal health care marketplaces met the criteria of covering all seven available SC medications without patient cost-sharing. ${ }^{12}$ A potential reason could be that the provision of these therapies at no cost to the patient may be viewed as a costly option for health care payers. ${ }^{10}$

Moreover, there is little research that examines whether reduction of smoking rates results in budgetary savings from potential cost offsets. A prior published budget impact model showed relatively low annual budgetary impact of providing coverage for two quit attempts with access to seven types of SC medications with zero patient cost-sharing requirement for Medicare, Medicaid, and commercial plans, but did not address cost offsets and examined trends for a maximum of 5 years. ${ }^{13}$ Further, a previously published cost-benefit analysis (CBA) demonstrated substantial savings in a Medicaid SC benefit program in Massachusetts (ie, inpatient savings per participant of \$571 [range: \$549-\$583]). ${ }^{14}$ However, this study was limited to a state Medicaid program with a 2-year study time horizon, and was not inclusive of all currently available prescription treatments indicated for SC.

The objective of this study was to estimate the net economic impact of providing SC prescription treatment coverage in both governmental and private health plans. Specifically, a CBA was conducted to estimate the pharmacy costs, medical cost offsets, and overall return on investment (ROI) of providing prescription SC treatment coverage for Medicare, Medicaid, and commercial health plan populations over a longer time horizon of 10 years.

\section{Methods \\ Overview of model framework}

A Markov chain model with five health states was used to simulate patterns of quit attempts, smoking relapse, and cessation success (Figure 1). This closed cohort model has been described in a previous work that estimated the pharmacy budget impact of SC coverage. ${ }^{13}$ The model was developed from a payer perspective, and incorporates the Medicare (federal health insurance), Medicaid (jointly funded by the federal government and states), and commercial health plan (employer-sponsored or self-insured) channels. Similar to the previous model, a 6-month model cycle length was utilized. The impact of smoking on morbidity and associated health care costs and resource utilization is multifactorial, with benefits building over time in tandem with increasing risks of key smoking-related comorbidities and avoidable events. ${ }^{2}$ As such, a 10-year time horizon was chosen to best balance the need to look beyond a short time frame to capture the impact of changing trajectory of risk with the more mediumterm budgetary decision-making utilized by US health care payers who fund SC products. 


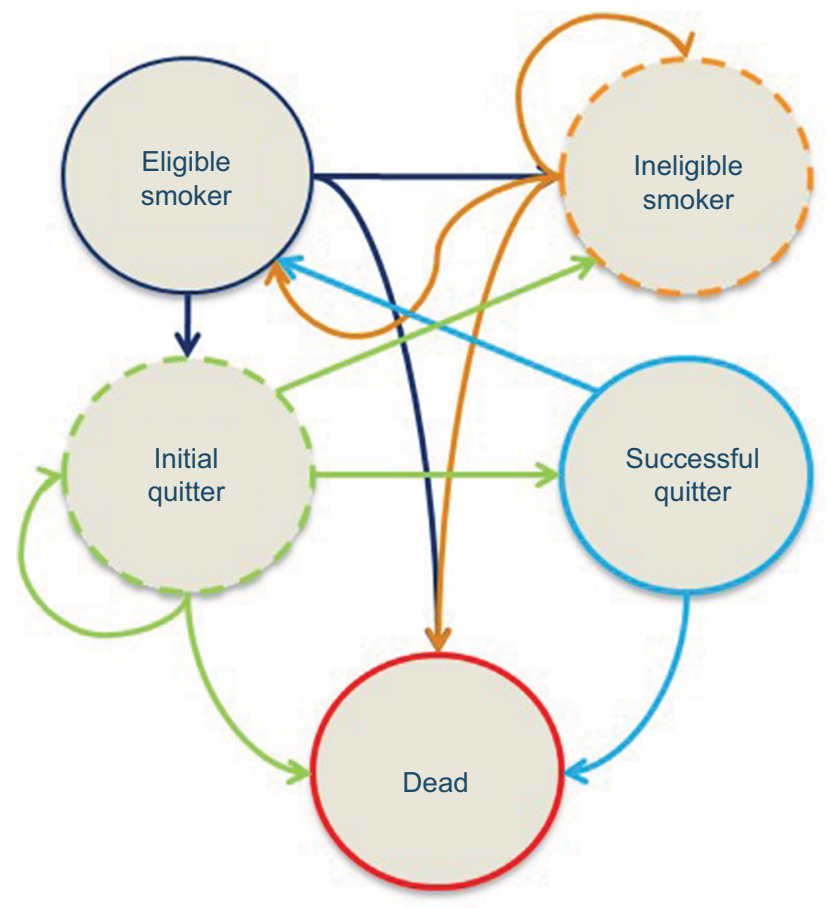

Figure I Markov chain diagram.

Notes: Health state descriptions:

Eligible smoker: Adult smokers who are eligible to quit smoking with a smoking cessation therapy during the current year. This includes:

I. smokers who have never attempted to quit,

2. smokers who have previously attempted to quit and failed,

3. successful quitters who subsequently relapsed.

Ineligible smoker: This tunnel state is used when modeling one covered quit attempt per year. A tunnel state is a state that can be occupied for only one cycle, which represents both the disease state the individual is in and the number of previous cycles spent in the state. ${ }^{29}$ The use of tunnel states helps to build artificial memory in Markov approaches, which normally have no memory over time. This state holds smokers who are not eligible to quit smoking because they failed a quit attempt $<12$ months prior to their current quit attempt. When modeling two quit attempts per year, smokers return to "Eligible Smoker" in the first cycle after their relapse. Initial quitter: A tunnel state for smokers who have attempted to quit in the current year, and are currently abstinent from smoking during the current cycle but who have not yet met the criteria for "Successful Quitter".

Successful quitter: Consists of initial quitters who have abstained from smoking for the required length of time to meet the clinical definition of success and who have not relapsed. The model assumes that a person becomes a "Successful Quitter" after being abstinent from smoking for I full year.

Dead: Captures death due to all-cause mortality, based on age- and gender-adjusted rates from US life tables from the Centers for Disease Control and Prevention. Reprinted by permission from Springer Nature. Adv Ther, Estimated budget impact of adopting the affordable care act's required smoking cessation coverage on United States healthcare payers, Baker CL, Ferrufino CP, Bruno M, Kowal S, 2017;34(I): 156-170, copyright 2018. ${ }^{13,21}$

This study uses a CBA approach to estimate the ROI of providing prescription SC treatments, based on estimated pharmacy costs and savings from smoking-attributable medical expenditures among Medicare, Medicaid, and commercial plan enrollees. The CBA approach incorporated nationallevel population demographics (ie, the age and gender distribution of the enrollee population in Medicare, Medicaid, and commercial plans), as well as national estimates for the prevalence of smoking, proportion of smokers attempting to quit, and the utilization of SC products to estimate the population of smokers using prescription SC products.

Seven FDA-approved forms of SC prescription products, including five forms of nicotine replacement therapy (NRT) (patch, gum, lozenge, nasal spray, and inhalers) when obtained through prescription and two non-NRT medications (bupropion SR and varenicline), were included in the analysis. ${ }^{15}$ The total cost of SC medications was estimated as the sum of per-prescription cost for SC products, multiplied by the number of smokers who are attempting to quit with each product, as derived from the Markov model.

The model estimated the economic benefit of SC products in terms of smoking-attributable medical expenditures, as described below. The net cost savings and ROI of prescription SC treatment by payer type were estimated based on the proportion of health care expenditure covered by each payer (ie, Medicare, Medicaid, and commercial health plans) vs patients' OOP costs. ${ }^{16-18}$ All costs and medical benefits were adjusted and reported in 2017 US dollars.

\section{Model inputs}

Epidemiology estimates, clinical efficacy, and smokingattributable medical expenditures used in this study were derived from peer-reviewed literature and publicly available data sources. Drug cost, market share, and patient cost-sharing data were obtained from the IQVIA National Prescription Audit ${ }^{\mathrm{TM}}$ (NPA) data. ${ }^{19}$ Three separate analyses were conducted on a hypothetical health plan with 1 million covered lives from Medicare, Medicaid, or commercial payer perspectives, respectively.

\section{Population distribution}

We used the age and gender distribution of the US population from the US census, ${ }^{20}$ prevalence of smoking derived from CDC Morbidity and Mortality Weekly Report data, ${ }^{1}$ and annual quit attempts and the utilization rate of SC prescriptions collected from the literature ${ }^{8,22}$ to estimate the population of patients using SC medications filled through a prescription (Table 1). The population cohorts were divided into five age bands: $8-17,18-34,35-49,50-64$, and 65 or older. The model allowed for patients to age into the next chronologic age group over the 10-year time horizon. As such, demographics for age band of 8-17 were also included in the population calculation to account for members who would age into the 18-34 group over the model's 10-year time horizon. USA all-cause mortality rates specific by age were utilized to account for deaths in each age band. ${ }^{21}$ Differential use of prescription SC products was not available 
Table I Population inputs (commercial and Medicaid payer channels)

\begin{tabular}{|c|c|c|c|c|c|c|}
\hline \multirow{2}{*}{$\begin{array}{l}\text { Population distribution } \\
\text { by age band (years) })^{20}\end{array}$} & \multicolumn{2}{|c|}{ Male population } & \multicolumn{2}{|c|}{ Female population } & \multicolumn{2}{|c|}{ Total plan population } \\
\hline & $\%$ & $\mathbf{N}$ & $\%$ & $\mathbf{N}$ & \multicolumn{2}{|l|}{$\overline{\mathbf{N}}$} \\
\hline \multicolumn{7}{|c|}{ Inputs to estimate adult smokers } \\
\hline $0-7$ & 5.0 & 50,459 & 4.8 & 48,248 & \multicolumn{2}{|l|}{98,707} \\
\hline $8-17$ & 6.5 & 64,955 & 6.2 & 62,235 & \multicolumn{2}{|l|}{127,190} \\
\hline $18-34$ & 11.9 & 119,087 & 11.4 & $1 \mid 4,312$ & \multicolumn{2}{|l|}{233,399} \\
\hline $35-49$ & 9.4 & 94,480 & 9.5 & 95,132 & \multicolumn{2}{|l|}{189,612} \\
\hline $50-64$ & 9.5 & 94,612 & 10.0 & 100,170 & \multicolumn{2}{|l|}{194,782} \\
\hline $65+$ & 6.9 & 69,432 & 8.7 & 86,879 & \multicolumn{2}{|l|}{$|56,3| \mid$} \\
\hline Overall & 49.3 & 493,025 & 50.7 & 506,975 & \multicolumn{2}{|l|}{$1,000,000$} \\
\hline Prevalence of smoking' & $\%$ & $\mathrm{~N}$ & $\%$ & $\mathrm{~N}$ & \multicolumn{2}{|l|}{$\mathrm{N}$} \\
\hline $0-7$ & 0.0 & 0 & 0.0 & 0 & \multicolumn{2}{|l|}{0} \\
\hline $8-17$ & 7.5 & 4,872 & 5.5 & 3,423 & \multicolumn{2}{|l|}{8,295} \\
\hline $18-34$ & 15.0 & 17,863 & 11.0 & 12,574 & \multicolumn{2}{|l|}{30,437} \\
\hline $35-49$ & 19.8 & 18,707 & 15.8 & $|5,03|$ & \multicolumn{2}{|l|}{33,738} \\
\hline $50-64$ & 17.9 & 16,935 & 16.1 & 16,127 & \multicolumn{2}{|l|}{33,063} \\
\hline $65+$ & 9.7 & 6,735 & 7.3 & 6,342 & \multicolumn{2}{|l|}{13,077} \\
\hline Overall & 13.2 & 65,112 & 10.6 & 53,498 & \multicolumn{2}{|l|}{118,610} \\
\hline \multirow[t]{2}{*}{ Age band (years) } & \multicolumn{2}{|c|}{$\begin{array}{l}\text { Population attempting } \\
\text { to quit }\end{array}$} & \multicolumn{2}{|c|}{$\begin{array}{l}\text { Population using smoking cessation } \\
\text { therapies (prescription or OTC) }\end{array}$} & \multicolumn{2}{|c|}{$\begin{array}{l}\text { \% Using smoking cessation } \\
\text { prescription products }^{22}\end{array}$} \\
\hline & $\%$ & $\mathbf{N}$ & $\%$ & $\mathbf{N}$ & $\%$ & $\mathbf{N}$ \\
\hline \multicolumn{7}{|c|}{ Inputs to estimate eligible quitters } \\
\hline $18-34$ & 66.7 & 20,302 & 15.6 & 3,167 & 25.4 & 804 \\
\hline $35-49$ & 59.8 & 20,175 & 25.6 & 5,165 & 25.4 & 1,312 \\
\hline $50-64$ & 49.6 & 16,399 & 37.7 & 6,182 & 25.4 & 1,570 \\
\hline $65+$ & 47.2 & 6,172 & 33.7 & 2,080 & 25.4 & 528 \\
\hline Overall & 57.2 & 63,049 & 26.3 & 16,595 & 25.4 & 4,215 \\
\hline
\end{tabular}

Abbreviation: OTC, over-the-counter.

by age group; therefore, a single average value was applied across all ages.

\section{Smoking cessation prescription utilization, pricing, and cost sharing}

The utilization of SC prescriptions was calculated top-down based on population trends. First, we identified the proportion of smokers attempting to quit, including attempts using SC therapies (prescription or OTC drugs) and attempts made without the assistance of SC therapies (ie, "cold turkey"). ${ }^{8}$ Next, we estimated the percentage of smokers within the plan using SC therapies (prescription and OTC) to quit smoking. ${ }^{8}$ Finally, we took into account the proportion of smokers who used prescription SC prescription products (assumed to be $25.4 \%$ across all payer types and age groups) among population using prescription and OTC medications. ${ }^{8}$ By applying the above steps to our population cohorts by age group, the model identifies target smokers for possible intervention. Detailed information on the inputs and patient counts for commercial and Medicaid plans is shown in Table 1. Using similar rates but a restricted age of 65 and above, total patients in the Medicare scenario were 83,603 smokers, 39,461 smokers attempting to quit, 13,298 using SC aids, and 3,378 using prescription smoking aids.

Real-world utilization, pricing, and patient cost sharing of SC prescription products were obtained from the IQVIA NPA data as of February $2017 .{ }^{19}$ The IQVIA NPA data is the industry standard for measuring the weekly/monthly outflow of prescriptions from retail pharmacies, mail service houses, or long-term care facilities into the hands of consumers, covering over $90 \%$ of all retail pharmacies, up to $75 \%$ of mail order and $83 \%$ of long-term care prescriptions. Prescription volume data of seven SC prescription products were obtained from the NPA database, which was then transformed back to patient-level utilization by dividing the number of prescriptions by the average number of packs or refills needed per patient to complete a single course of SC therapy (Table 2).

The base-case model evaluates a health care program with open access (no copay) to SC prescriptions, that is, copayment relief under ACA (all FDA-approved tobacco cessation medications be covered without prior authorization or patient cost sharing). Contracted cost per prescription was calculated 
Table 2 Inputs for market share and drug costs in the base case

\begin{tabular}{|c|c|c|c|c|c|}
\hline \multirow[t]{2}{*}{ Product type } & \multirow{2}{*}{$\begin{array}{l}\text { Utilization } \\
\text { (market share) } \\
\text { distribution (\%) }\end{array}$} & \multicolumn{2}{|c|}{$\begin{array}{l}\text { Plan cost per prescription (open } \\
\text { access, without copay) }\end{array}$} & \multirow{2}{*}{$\begin{array}{l}\text { Contracted } \\
\text { cost per } \\
\text { prescription }^{b}\end{array}$} & \multirow[t]{2}{*}{$\begin{array}{l}\text { Prescriptions } \\
\text { per therapy }\end{array}$} \\
\hline & & Unit cost ${ }^{a}$ & $\begin{array}{l}\text { Units per } \\
\text { prescription }^{a}\end{array}$ & & \\
\hline \multicolumn{6}{|l|}{ Commercial payer } \\
\hline Varenicline & 74.46 & $\$ 5.71$ & 55.42 & $\$ 316.43$ & 3 \\
\hline Bupropion & 5.12 & $\$ 0.60$ & 59.76 & $\$ 35.86$ & 3 \\
\hline NRT inhaler & 1.48 & $\$ 1.88$ & 183.93 & $\$ 345.79$ & 3 \\
\hline NRT nasal spray & 0.46 & $\$ 8.34$ & 46.24 & $\$ 385.67$ & 3 \\
\hline NRT gum & 3.41 & $\$ 0.26$ & 135.33 & $\$ 35.19$ & 3 \\
\hline NRT lozenge & 1.07 & $\$ 0.35$ & 120.10 & $\$ 42.04$ & 4 \\
\hline NRT patch & 14.00 & $\$ 1.69$ & 25.23 & $\$ 42.63$ & 5 \\
\hline \multicolumn{6}{|l|}{ Medicaid payer } \\
\hline Varenicline & 40.72 & $\$ 5.74$ & 53.94 & $\$ 309.63$ & 3 \\
\hline Bupropion & 3.63 & $\$ 0.57$ & 54.85 & $\$ 31.27$ & 3 \\
\hline NRT inhaler & 1.59 & $\$ 1.88$ & 175.43 & $\$ 329.81$ & 3 \\
\hline NRT nasal spray & 0.22 & $\$ 8.32$ & 41.30 & $\$ 343.65$ & 3 \\
\hline NRT gum & 15.12 & $\$ 0.25$ & 129.96 & $\$ 32.49$ & 3 \\
\hline NRT lozenge & 3.24 & $\$ 0.37$ & 117.12 & $\$ 43.34$ & 4 \\
\hline NRT patch & 35.48 & $\$ 1.74$ & 23.83 & $\$ 4 I .46$ & 5 \\
\hline \multicolumn{6}{|l|}{ Medicare payer } \\
\hline Varenicline & 81.76 & $\$ 5.73$ & 56.32 & $\$ 322.69$ & 3 \\
\hline Bupropion & 8.25 & $\$ 0.56$ & 68.24 & $\$ 38.22$ & 3 \\
\hline NRT inhaler & 4.10 & $\$ 1.87$ & 190.67 & $\$ 356.56$ & 3 \\
\hline NRT nasal spray & 1.65 & $\$ 8.29$ & 51.19 & $\$ 424.38$ & 3 \\
\hline NRT gum & 0.84 & $\$ 0.29$ & 133.16 & $\$ 38.62$ & 3 \\
\hline NRT lozenge & 0.28 & $\$ 0.39$ & 116.01 & $\$ 45.24$ & 4 \\
\hline NRT patch & 3.13 & $\$ 1.89$ & 24.48 & $\$ 46.26$ & 5 \\
\hline
\end{tabular}

Notes: a Drug unit cost and units per prescription were derived from IQVIA National Prescription Audit ${ }^{\text {TM }}$ (NPA) data. ${ }^{\mathrm{b}}$ Contracted cost per prescription was calculated as (Unit Cost $\times$ Units per Prescription - Patient Copay).

Abbreviation: NRT, nicotine replacement therapy.

based on drug unit cost, number of units per prescription, and a zero copayment rate under the base-case scenario (Table 2 ).

\section{Clinical efficacy}

Clinical efficacy rates for the seven SC prescription products of interest were based on data from a Cochrane systematic review. ${ }^{23}$ Unaided cessation success rate $(5.0 \%)$ and probability of late relapse (recidivism) (4.4\%) were derived from published literature. ${ }^{9,24}$ We used the recidivism rate of $4.4 \%$, an average value of both the primary study results and findings from the secondary studies reported in Wetter et al 2004, to estimate the number of successful quitters who had quit for at least 12 months but then eventually relapsed. More detailed information of efficacy for unaided and aided cessation were described in our previous publication on budget impact of SC..$^{13,24}$

\section{Smoking-attributable medical cost}

To estimate the cost offsets associated with SC, the model utilized smoking-attributable medical costs from the literature to derive the economic value of SC at the population level. Smoking-attributable medical costs per patient by sex and age were originally derived from Maciosek et al 2015, which assumed that $8.66 \%$ of USA Personal Health Care Expenditures was attributable to smoking. ${ }^{7}$ In that paper, the authors calculated smoking-attributable medical expenditures using a relative risk approach, and stratified their analysis by age group, sex, and smoking status (never, current, and former smokers). Because the health benefits of SC accrue over time following the initial quit (decay assumption), in this study, we applied a smooth function provided by Maciosek et al $2017\left(1-0.9927-1.086 \times \mathrm{e}^{\wedge}(-0.1171 \times \mathrm{t})\right)$ to calculate the smoking-attributable costs of each former smoker as a portion of a comparable current smoker's costs taking into account the decay assumption as $\mathrm{t}=$ years since quit. ${ }^{25}$ Furthermore, we reweighted the per-patient cost estimates based on population distribution by our age group categories (eg, 18-34, 35-49, 50-64, and 65+), as shown in Table 3. Using data from Kaiser Family Foundation and other published data sources, the analysis incorporated the proportion of 
Table 3 Annual smoking-attributable medical costs per patient ${ }^{\mathrm{a}}$

\begin{tabular}{|c|c|c|c|c|c|c|}
\hline \multirow[t]{2}{*}{ Age group } & \multicolumn{2}{|c|}{ Current smokers ${ }^{7,25}$} & \multicolumn{2}{|c|}{ Former smokers ${ }^{7,25}$} & \multicolumn{2}{|c|}{ Incremental cost } \\
\hline & Males & Females & Males & Females & Males & Females \\
\hline 18-34 & $\$ 1,639.82$ & $\$ 1,539.56$ & $\$ 1,000.99$ & $\$ 939.79$ & $\$ 638.82$ & $\$ 599.77$ \\
\hline $35-49$ & $\$ 1,639.82$ & $\$ 1,539.56$ & $\$ 1,000.99$ & $\$ 939.79$ & $\$ 638.82$ & $\$ 599.77$ \\
\hline $50-64$ & $\$ 4,213.54$ & $\$ 3,416.82$ & $\$ 2,572.07$ & $\$ 2,085.73$ & $\$ 1,641.47$ & $\$ 1,331.10$ \\
\hline $65+$ & $\$ 13,555.14$ & $\$ 12,424.74$ & $\$ 8,274.45$ & $\$ 7,584.42$ & $\$ 5,280.69$ & $\$ 4,840.32$ \\
\hline
\end{tabular}

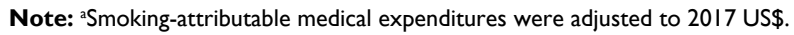

total health care expenditures covered by Medicare $(62 \%),{ }^{16}$ Medicaid (95.2\%), ${ }^{17}$ or commercial payers $(81.9 \%)^{18} \mathrm{vs}$ by patients' OOP spending or other sources, respectively, to isolate costs to payers.

\section{Assumptions and key outcome measures}

Our study made the following assumptions: First, population demographics, proportion of patients attempting to quit, proportion using SC prescription products, and market share distribution of the seven SC prescription products were consistent over the 10-year time horizon. Second, all smokers who attempt to quit entered the model to account for smokers who may successfully quit without SC therapies. Third, because published data suggest that relapse decreases as the duration of time since quitting increases, the model assumes that a person becomes a "Successful Quitter" after being abstinent from smoking for at least one full year and a single rate is used for late relapse among successful quitters irrespective of time since quitting. Fourth, drug unit cost per pill derived from NPA data includes the dispensing fee. Therefore, dispensing fee was assumed to be included in the overall prescription cost. Fifth, we assumed the same utilization of SC prescription products to quit smoking (25.4\%) across age groups, scenarios, and payer types in the base case. This percentage was used to calculate the percentage of "eligible" population for the model (ie, smokers who are attempting to quit annually with prescription products). In addition, the economic outcomes are at the population level, accounting for the status of current or former smokers in the population at the start of the simulation, and evaluates the population benefits accruing thereafter over time. Finally, in the base case, the model assumes a decay assumption as previously described with this economic data for estimating the accumulated health benefits associated with SC over time since initial quitting.

The following key outcome measures were estimated in this analysis: total number of successful quitters, total cost of SC medication, medical benefit (cost) of quitting, net economic benefit of quitting, and the ROI to a plan for providing $\mathrm{SC}$ benefit. The total number of successful quitters consists of initial quitters who have abstained from smoking for the required length of time to meet the clinical definition of success and who have not relapsed. By definition, a successful quitter must quit for at least 12 months before becoming a successful quitter. Detailed calculation steps of other key outcome measures are described in the legends for Figures 2-4.

\section{Base-case model scenario}

The base-case scenario was defined as the provision of two smoking quit attempts per year, with no associated copay, and a $25.4 \%$ utilization rate of SC prescriptions. This scenario reflects the ACA recommendation of allowing up to two quit attempts per year with no patient cost sharing. The results for the base-case scenario from the three payer channels (ie, commercial, Medicaid, and Medicare) are reported in this paper to highlight the potential ROI for a plan with the ACA-recommended coverage.

\section{Statement for ethics}

Most of the data sources are publicly available, except for the IQVIA National Prescription Audit ${ }^{\mathrm{TM}}$ (NPA) data. No IRB approval was needed for this study given that no human subjects were included. This is an economic model developed from secondary data. Unpublished data from this study, specifically market share and daily average consumption data for prescription smoking cessation products, can be made available to editors and reviewers upon request to the corresponding author.

\section{Results}

For hypothetical nationally representative commercial or Medicaid plans consisting of 1 million covered lives, $\sim 63,049$ adult smokers in each plan will attempt to quit in a given year. Of those attempting to quit, 16,595 smokers will use smoking cessation therapies (either prescription or OTC drug), of 


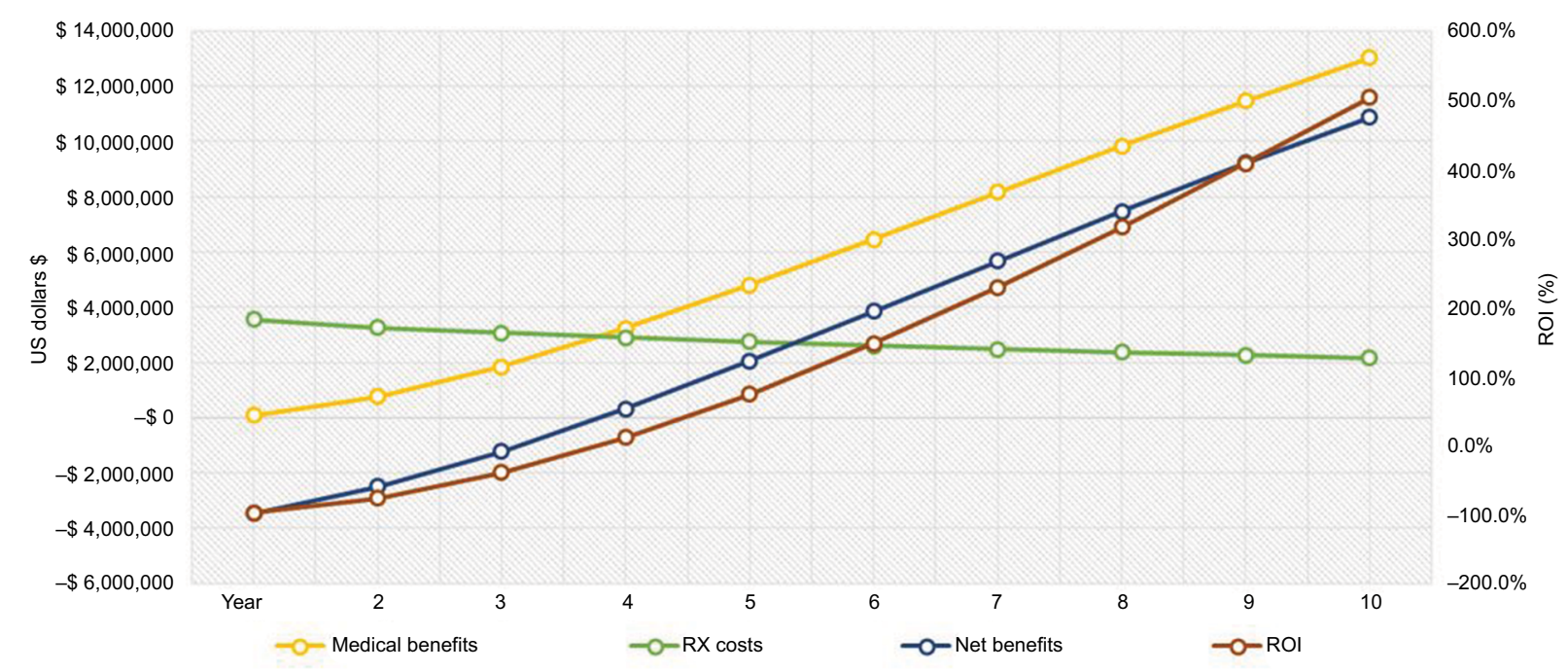

\begin{tabular}{|c|c|c|c|c|c|c|c|c|c|c|c|}
\hline Year & 1 & 2 & 3 & 4 & 5 & 6 & 7 & 8 & 9 & 10 & Total \\
\hline $\begin{array}{l}\text { Discounted benefits } \\
\text { from successful } \\
\text { quitters (\$) } \\
\end{array}$ & 83,555 & 753,648 & $1,848,578$ & $3,231,659$ & $4,796,386$ & $6,460,001$ & $8,158,499$ & $9,842,906$ & $11,474,770$ & $13,029,349$ & $59,679,351$ \\
\hline $\begin{array}{l}\text { Discounted total cost } \\
\text { of smoking cessation } \\
\text { prescriptions (\$) }\end{array}$ & $3,548,829$ & $3,249,731$ & $3,069,808$ & $2,904,079$ & $2,751,731$ & $2,612,036$ & $2,484,446$ & $2,367,311$ & $2,258,540$ & $2,156,854$ & $27,403,366$ \\
\hline $\begin{array}{l}\text { Net economic benefit } \\
\text { (\$) }\end{array}$ & $-3,465,274$ & $-2,496,084$ & $-1,221,230$ & 327,579 & $2,044,656$ & $3,847,965$ & $5,674,052$ & $7,475,595$ & $9,216,230$ & $10,872,495$ & $32,275,985$ \\
\hline ROI & $-97.6 \%$ & $-76.8 \%$ & $-39.8 \%$ & $11.3 \%$ & $74.3 \%$ & $147.3 \%$ & $228.4 \%$ & $315.8 \%$ & $408.1 \%$ & $504.1 \%$ & $117.8 \%$ \\
\hline
\end{tabular}

Figure 2 Outcome measures for commercial payers.

Notes: The graph illustrates the trend for costs, benefits, and ROI ratio over 10 years. The green line represents the trend for smoking cessation prescription drug costs. The yellow line describes the medical benefits of smoking-attributable medical costs avoided. The blue line represents the net economic benefits (medical benefits - costs of smoking cessation prescriptions). The dark red line shows the trend for ROI change. The horizontal axis shows the time in years; the vertical axis on the left shows cost in 2017 US\$; the vertical axis on the right demonstrates percentage (\%) for ROI ratio = net divided by program costs. Descriptions of key outcome measures reported in the table: (I) Total medical benefits from successful quitters were estimated from smoking-attributable medical costs per patient by sex and age group (ie, I8-34, 35-49, 50-64, and 65+).7,25; (2) The total cost of smoking cessation prescription medications was calculated from the utilization and pricing of smoking cessation medications; (3) Net savings (net economic benefits) were estimated as I) minus 2), that is, the benefits in excess of estimated costs for implementing smoking cessation prescription coverage program; (4) ROI outcome measure was calculated by (I) minus (2), that is, the excess benefits divided by total costs of smoking cessation prescriptions. The net present value of costs and benefits is discounted $3 \%$ for future costs.

Abbreviations: ROI, return on investment; RX, prescription.

which only 4,215 will utilize smoking cessation prescription products (Table 1). For a hypothetical Medicare plan consisting of 1 million enrollees, 13,298 of 39,461 smokers aged above 65 will attempt to quit using smoking cessation therapies (prescription or OTC), of which only 3,378 will utilize smoking cessation prescriptions.

In the base case (two covered quit attempts and no patient cost-sharing), the total number of successful quitters using smoking cessation prescription products over 10 years were estimated to be 6,853 for commercial payers, 6,115 for Medicaid, and 4,986 for Medicare plans.

Over the 10-year time horizon, the number of new successful quitters will decrease annually because of the decreasing number of prevalent smokers in each subsequent year (given accumulating successful quits as well as mortality). Therefore, the total drug costs of smoking cessation prescriptions decrease over time (represented by the green line in Figures 2-4). On the other hand, the medical benefits attributable to former smokers accrue with a steady increasing trend and a slightly declining trend for the total prescription costs, thereby increasing the net health benefit to the plan (Figures 2-4). The ROI would gradually increase from a negative value in the first year to a positive value $(11.3 \%$ for commercial plan and $78.4 \%$ for Medicaid plan with a net economic benefit of $\$ 327,579$ and $\$ 1,469,834$, respectively) in the fourth year since quitting. For Medicare payer, the ROI has become a positive value of $30.6 \%$ ( $\$ 801,132$ net economic benefit) from the third year since smoking cessation. On average, over the 10-year follow-up, the provision of up to two quit attempts per year with no patient cost sharing will yield a return of $\$ 1.18, \$ 2.50$, and $\$ 3.22$ savings for every dollar spent on smoking cessation prescriptions for commercial, 


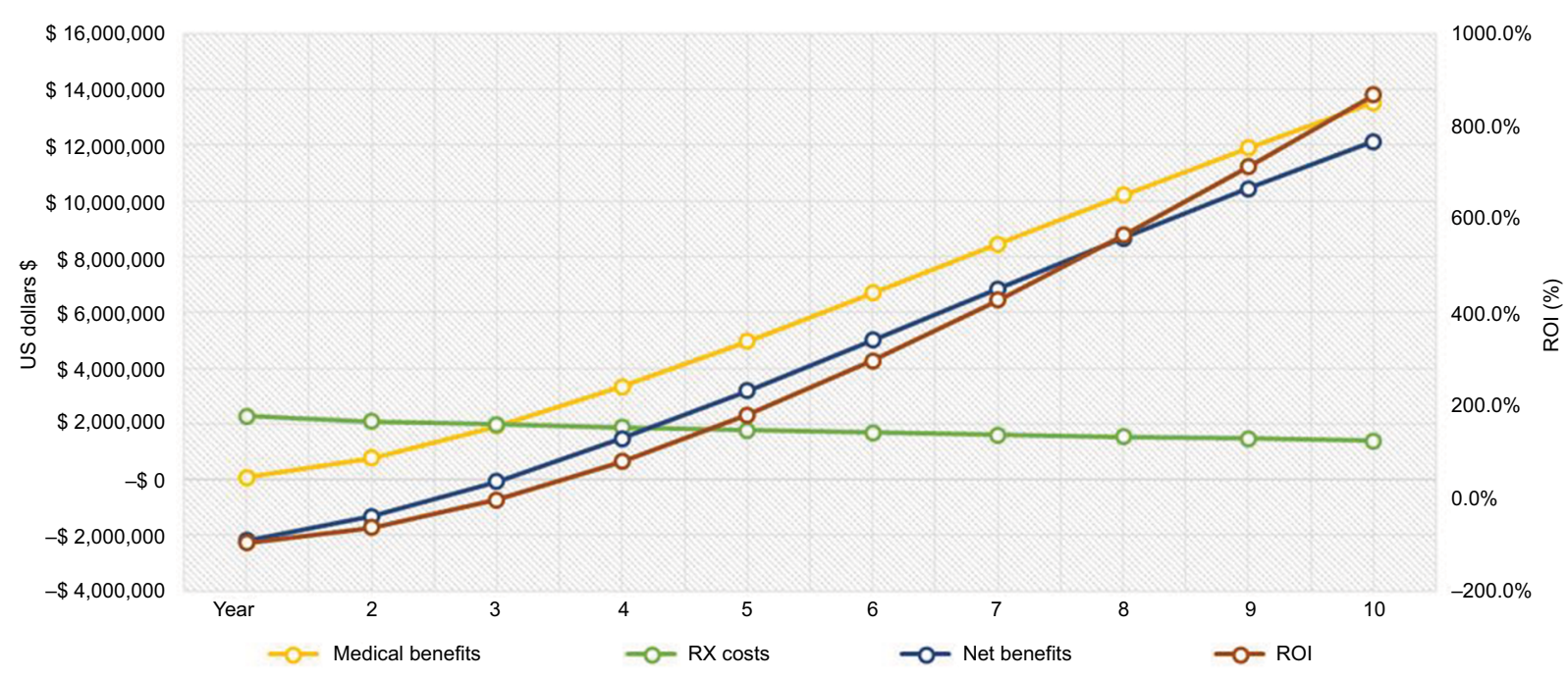

\begin{tabular}{|c|c|c|c|c|c|c|c|c|c|c|c|}
\hline Year & 1 & 2 & 3 & 4 & 5 & 6 & 7 & 8 & 9 & 10 & Total \\
\hline $\begin{array}{l}\text { Discounted benefits } \\
\text { from successful } \\
\text { quitters (\$) }\end{array}$ & 86,307 & 778,918 & $1,911,659$ & $3,343,827$ & $4,965,630$ & $6,691,608$ & $8,455,536$ & $10,206,627$ & $11,904,892$ & $13,524,509$ & $61,869,511$ \\
\hline $\begin{array}{l}\text { Discounted total cost } \\
\text { of smoking cessation } \\
\text { prescriptions (\$) }\end{array}$ & $2,283,514$ & $2,093,175$ & $1,979,169$ & $1,873,993$ & $1,777,163$ & $1,688,250$ & $1,606,935$ & $1,532,184$ & $1,462,672$ & $1,397,598$ & $17,694,652$ \\
\hline $\begin{array}{l}\text { Net economic benefit } \\
\text { (\$\$) }\end{array}$ & $-2,197,207$ & $-1,314,257$ & $-67,510$ & $1,469,834$ & $3,188,467$ & $5,003,358$ & $6,848,601$ & $8,674,443$ & $10,442,220$ & $12,126,911$ & $44,174,859$ \\
\hline ROI & $-96.2 \%$ & $-62.8 \%$ & $-3.4 \%$ & $78.4 \%$ & $179.4 \%$ & $296.4 \%$ & $426.2 \%$ & $566.1 \%$ & $713.9 \%$ & $867.7 \%$ & $249.7 \%$ \\
\hline
\end{tabular}

Figure 3 Outcome measures for Medicaid payers.

Notes: The graph illustrates the trend for costs, benefits, and ROI ratio over 10 years. The green line represents the trend for smoking cessation prescription drug costs. The yellow line describes the medical benefits of smoking-attributable medical costs avoided. The blue line represents the net economic benefits (medical benefits - costs of smoking cessation prescriptions). The dark red line shows the trend for ROI change. The horizontal axis shows the time in years; the vertical axis on the left shows cost in 2017 US\$; the vertical axis on the right demonstrates percentage (\%) for ROI ratio = net divided by program costs. Descriptions of key outcome measures reported in the table: (I) Total medical benefits from successful quitters were estimated from smoking-attributable medical costs per patient by sex and age group (ie, I8-34, 35-49, 50-64, and $65+) .7,25$; (2) The total cost of smoking cessation prescription medications was calculated from the utilization and pricing of smoking cessation medications; (3) Net savings (net economic benefits) were estimated as I) minus 2), that is, the benefits in excess of estimated costs for implementing smoking cessation prescription coverage program; (4) ROI outcome measure was calculated by (I) minus (2), that is, the excess benefits divided by total costs of smoking cessation prescriptions. The net present value of costs and benefits is discounted $3 \%$ for future costs.

Abbreviations: ROI, return on investment; RX, prescription.

Medicaid, and Medicare plans, respectively (Figures 2-4). The relatively higher ROI for Medicare vs commercial and Medicaid plans, is driven by the higher annual direct health care costs in the older Medicare population, and, therefore, the higher associated potential cost offsets from smoking cessation.

Univariate sensitivity analysis (testing a range of $20 \%$ above and below default values) was performed on key variables to test the impact of changing input assumptions on model results. Model results consistently showed ROI above $100 \%$ across all three payer perspectives across changes to key inputs, highlighting that the model results of a positive ROI are robust. The model was most sensitive to the exclusion of the decay assumption when estimating smoking-attributable costs, and followed by the percentage of total health care expenditures covered by the payer. The exclusion of the decay assumption assumes an average health benefit value, regardless of time since quit. When the decay assumption is excluded, the average increase in ROI over 10 years was $240.7 \%, 535.8 \%$, and $446.8 \%$ for commercial, Medicare, and Medicaid plans, respectively.

\section{Discussion}

In this study, we analyzed the benefits of providing smoking cessation prescription medications in a health care program with two smoking quit attempts per year and no copayment (or the ACA recommended coverage scenario). We reported that smoking cessation treatment would enable 6,853 smokers for commercial, 6,115 for Medicaid, and 4,986 for Medicare plans to quit over 10 years. The model demonstrated that ROI became positive by year 3 for Medicare and by year 4 for commercial and Medicaid. Looking at the total investment 


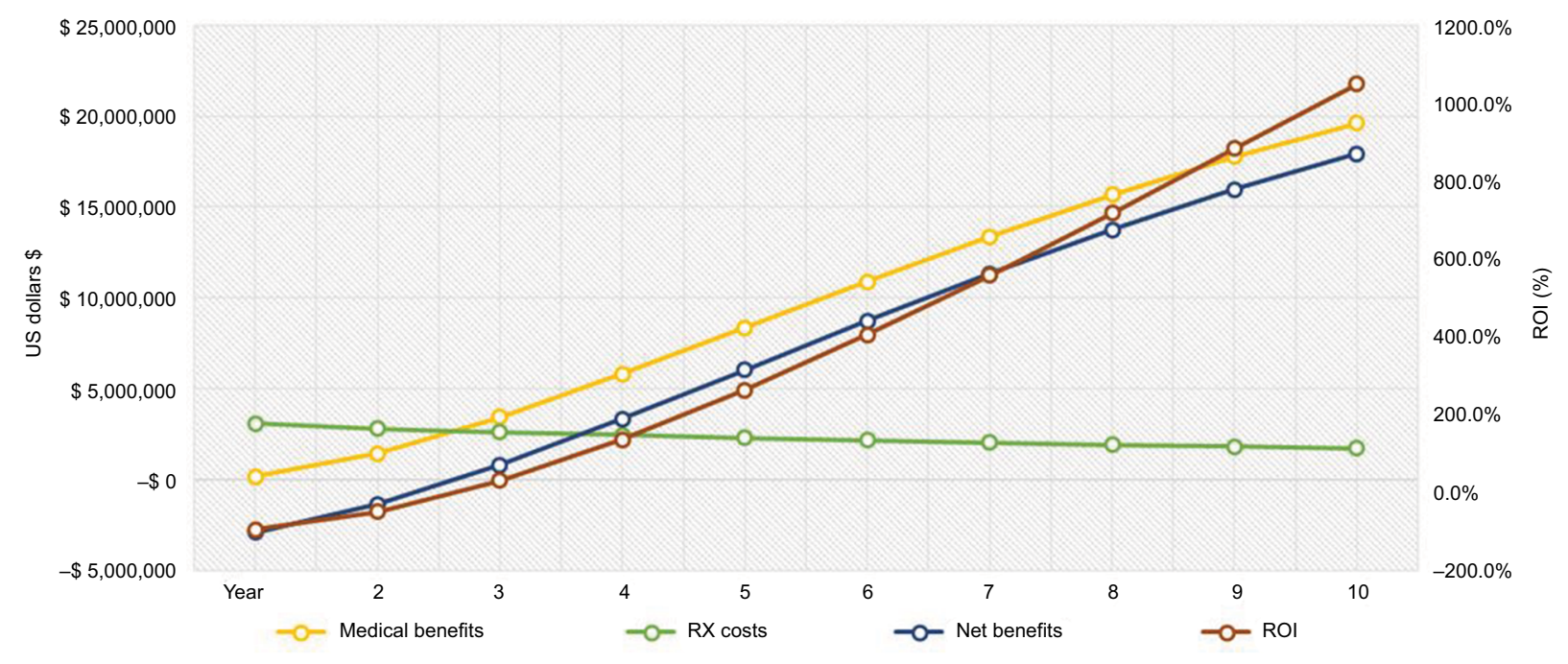

\begin{tabular}{|c|c|c|c|c|c|c|c|c|c|c|c|}
\hline Year & 1 & 2 & 3 & 4 & 5 & 6 & 7 & 8 & 9 & 10 & Total \\
\hline $\begin{array}{l}\text { Discounted benefits } \\
\text { from successful } \\
\text { quitters (\$) }\end{array}$ & 159,454 & $1,435,211$ & $3,418,348$ & $5,794,614$ & $8,341,242$ & $10,901,262$ & $13,367,233$ & $15,668,706$ & $17,762,582$ & $19,625,747$ & $96,474,398$ \\
\hline $\begin{array}{l}\text { Discounted total cost } \\
\text { of smoking cessation } \\
\text { prescriptions (\$) }\end{array}$ & $3,085,923$ & $2,798,001$ & $2,617,216$ & $2,451,790$ & $2,300,197$ & $2,161,069$ & $2,033,187$ & $1,915,458$ & $1,806,905$ & $1,706,653$ & $22,876,399$ \\
\hline $\begin{array}{l}\text { Net economic benefit } \\
\text { (\$) }\end{array}$ & $-2,926,469$ & $-1,362,790$ & 801,132 & $3,342,824$ & $6,041,045$ & $8,740,192$ & $11,334,046$ & $13,753,248$ & $15,955,678$ & $17,919,094$ & $73,597,999$ \\
\hline
\end{tabular}

Figure 4 Outcome measures for Medicare payers.

Notes: The graph illustrates the trend for costs, benefits and ROI ratio over 10 years. The green line represents the trend for smoking cessation prescription drug costs. The yellow line describes the medical benefits of smoking-attributable medical costs avoided. The blue line represents the net economic benefits (medical benefits - costs of smoking cessation prescriptions). The dark red line shows the trend for ROI change. The horizontal axis shows the time in years; the vertical axis on the left shows cost in 2017 US\$; the vertical axis on the right demonstrates percentage (\%) for ROI ratio = net divided by program costs. Descriptions of key outcome measures reported in the table: (I) Total medical benefits from successful quitters were estimated from smoking-attributable medical costs per patient by sex and age group (ie, I8-34, 35-49, 50-64, and $65+) .7,25$; (2) The total cost of smoking cessation prescription medications was calculated from the utilization and pricing of smoking cessation medications; (3) Net savings (net economic benefits) were estimated as (I) minus (2), that is, the benefits in excess of estimated costs for implementing smoking cessation prescription coverage program; (4) ROI outcome measure was calculated by (I) minus (2), that is, the excess benefits divided by total costs of smoking cessation prescriptions. The net present value of costs and benefits is discounted $3 \%$ for future costs.

Abbreviations: ROI, return on investment; RX, prescription.

over 10 years, for each dollar invested in smoking cessation prescription products, the average net economic benefit for return is up to $\$ 3.22$ dollars per year (for Medicare plans) over 10 years.

The findings of this study resonate with other publications that have examined ROI for smoking cessation programs. However, results from this work build on the existing literature to show a holistic picture of cost impact, considering both the cost of smoking cessation medications as well as estimated cost offsets over an extended time horizon that better captures the medium to long-term impact of smoking cessation. For example, a study on the Massachusetts Medicaid Cessation Benefit program showed that the state saved $\$ 571$ in inpatient costs per participant, for about $\$ 183$ per participant in program costs. ${ }^{14}$ Savings in medical costs were estimated to be $\$ 3.12$ for every $\$ 1$ spent on the Medicaid cessation program, yielding an ROI of $\$ 2.12$ per $\$ 1$ spent. ${ }^{14}$ Our study expanded the scope of analysis from a state Medicaid program to a national study, lengthened the time horizon from 2 to 10 years, and included FDA-approved smoking cessation medications not included in the Massachusetts study, which were unavailable at the time of the study. Consistent with the Massachusetts study, our findings suggest positive cost savings (net benefits) with ACA-recommended smoking cessation program, yielding an average return of $\$ 2.50$ for Medicaid with ROI ranging from $-\$ 0.96$ (year 1 ) to $\$ 8.68$ (year 10).

Further, a previously published budget impact model for smoking cessation programs estimated that the per-member per-month (PMPM) cost of providing coverage of smoking 
cessation medications was $\$ 0.10$ for commercial, $\$ 0.06$ for Medicare, and \$0.07 for Medicaid plans (assuming 7.4\% utilization rate of smoking cessation prescription products). ${ }^{13}$ This study builds on that work to incorporate potential cost benefits and to evaluate how expenditures would change with a higher utilization of prescription medications (a 25.4\% rate). Putting the findings of this study into a PMPM context, we found that the monthly cost of smoking cessation prescription products per member ranges from $\$ 0.30$ (year 1) to $\$ 0.18$ (year 10) in a comprehensive coverage scenario with no copay. The difference in PMPM estimates between the two studies is a result of the increased utilization rate as well as minor drug cost changes in the current analysis. Using an assumed utilization rate of $7.4 \%$ in this updated model, PMPM estimates for year 1 (and on average over the 10 years) are in line with projections from the previously published BIM for commercial $(\$ 0.09$ year $1 ; \$ 0.08$ 10 -year average), Medicare $(\$ 0.08 ; \$ 0.07)$, and Medicaid (\$0.06; \$0.05). A lower utilization of $7.4 \%$ decreases the ROI to $\$ 1.18, \$ 2.49$, and $\$ 3.20$ savings for every dollar spent on smoking cessation prescriptions for commercial, Medicaid, and Medicare plans compared to the base-case scenario over 10 years.

Similar to any economic model, this CBA is subject to several limitations, which should be considered when interpreting results. First, the data on utilization and costs for smoking cessation intervention are based on real-world estimates derived from the IQVIA NPA data. While this dataset covers most of the prescription channels (pharmacy retail, mail order), it only covers prescriptions across $86 \%$ of all standard and specialty markets and projects the remaining $14 \%$. Second, the model relies on the use of published efficacy rates derived from systematic reviews and meta-analyses for indirect comparison given that head-to-head trial data are not available for all comparators in the analysis. Third, the model only estimates the costs and benefits associated with the use of smoking cessation prescription products. However, in the real world, many smokers will attempt to quit either unaided or using nonprescription OTC products and they may also utilize behavioral counseling programs (either individual or group), which will enhance their likelihood of success resulting in greater economic savings. In such cases, the plan would gain additional economic benefit without a direct cost incurred, and therefore, the overall net economic benefit reported in this model may be underestimated. Fourth, the analysis does not account for drug adherence - it assumes that all patients who attempt to quit undergo a full course of therapy as prescribed. Fourth, the analysis does not explore health care resource utilization changes that may result from the removal of patient cost sharing. Finally, given data gaps in estimating the use of prescription smoking cessation products by age, the model uses an average of $25.4 \%$ across all age groups. However, sensitivity analyses confirm that changes to population inputs (such as the percent of patients using smoking cessation medication) only scale the magnitude of costs and does not impact the relationship between costs and ROI in a meaningful way. Therefore, we concluded that the need to use a single estimate across age groups did not impact the overall interpretation of ROI.

Our study directly estimates the ROI of adopting ACArecommended smoking cessation coverage to a hypothetical US health plan (commercial, Medicaid, or Medicare). Given the proven efficacy of pharmacotherapy for smoking cessation, near-term investments in supporting the ACArecommended smoking cessation benefits will translate into a positive long-term ROI. As smoking is a leading cause of morbidity and preventable deaths in the USA, the availability of smoking cessation benefits could not only improve health outcomes (eg, reduced smoking-associated comorbidities and better health-related quality of life), but also reduce smokingattributable costs to payers over time. As such, public health initiatives such as Healthy People $2020,{ }^{26}$ the ACA, and the National Academy of Medicine identified tobacco control and chronic disease prevention as one of the key issue areas for vital directions for health and health care. ${ }^{27}$ While information on improvements in patient outcomes and patient quality of life resonate with patients, providers, and health care payers alike, health care payers must consider the fiscal burden of the initial investment in smoking decisions when operating within tight budgets. Therefore, it is important to consider the value of health care interventions both in terms of patient outcomes and in terms of economic impact. Findings of this study reinforce that adopting the ACA recommendations for smoking cessation coverage will have a limited near-term impact on health plans and significant potential long-term benefits.

\section{Conclusion}

The results of this analysis are consistent with prior research, which has demonstrated the efficacy and cost-effectiveness of certain drug therapies in reducing smoking and the health benefits of smoking cessation. ${ }^{28}$ Furthermore, utilizing real-world data, this study provides health care payers with a benchmark analysis regarding the economic benefit and ROI of investing in smoking cessation programs as they strive to balance health outcomes and costs, and illustrates 
the potential financial impact of short-term investments on longer-term savings.

\section{Data sharing statement}

Unpublished data from this study, specifically market share and daily average consumption data for prescription smoking cessation products, can be made available to editors and reviewers upon request to the corresponding author.

\section{Acknowledgments}

Sponsorship, article processing charges, and the open access charge for this study were funded by Pfizer Inc.

\section{Author contributions}

All named authors meet the International Committee of Medical Journal Editors (ICMJE) criteria for authorship for this manuscript, take responsibility for the integrity of the work as a whole, and have given final approval to the version to be published. All authors contributed toward data analysis, drafting and critically revising the paper and agree to be accountable for all aspects of the work.

\section{Disclosure}

CL Baker and P Subedi are employees and stockholders of Pfizer Inc. CP Ferrufino, Y Ding, J Tan, and S Kowal are employees of IQVIA, which received funding from Pfizer for conducting this study and for the development of this manuscript. The authors report no other conflicts of interest in this work.

\section{References}

1. Jamal A, King BA, Neff LJ, Whitmill J, Babb SD, Graffunder CM. Current cigarette smoking among adults - United States, 2005-2015. MMWR Morb Mortal Wkly Rep. 2016;65(44):1205-1211.

2. US Department of Health and Human. The Health Consequences of Smoking-50 Years of Progress: A Report of the Surgeon General, 2014 [Internet]. Atlanta, GA, USA; 2014 [cited March 28, 2017]. Available from: https://www.surgeongeneral.gov/library/ reports/50-years-of-progress/.

3. Xu X, Bishop EE, Kennedy SM, Simpson SA, Pechacek TF. Annual healthcare spending attributable to cigarette smoking: an update. $A m J$ Prev Med. 2015;48(3):326-333.

4. Jha P, Ramasundarahettige C, Landsman V, et al. 21st-century Hazards of smoking and benefits of cessation in the United States. N Engl J Med. 2013;368(4):341-350.

5. Mons U, Muezzinler A, Gellert C, et al. Impact of smoking and smoking cessation on cardiovascular events and mortality among older adults: Meta-analysis of Individual participant data from prospective cohort studies of the CHANCES consortium. BMJ. 2015;350:h1551.

6. Nash SH, Liao LM, Harris TB, Freedman ND. Cigarette smoking and mortality in adults aged 70 years and older: results from the NIH-AARP cohort. Am J Prev Med. 2017;52(3):276-283.
7. Maciosek MV, Xu X, Butani AL, Pechacek TF. Smoking-attributable medical expenditures by age, sex, and smoking status estimated using a relative risk approach. Prev Med. 2015;77:162-167.

8. Babb S, Malarcher A, Schauer G, Asman K Jamal A. Quitting smoking among adults - United States, 2000-2015. MMWR Morb Mortal Wkly Rep. 2017;65(52):1457-1464.

9. Foulds J, Burke M, Steinberg M, Williams JM, Ziedonis DM. Advances in pharmacotherapy for tobacco dependence. Expert Opin Emerg Drugs. 2004;9(1):39-53.

10. Centers for Disease Prevention and Control. Coverage for Tobacco Use Cessation Treatments [Internet page last updated: February 28, 2018]. [cited April 26, 2018]. Available from: https://www.cdc.gov/tobacco/ quit_smoking/cessation/pdfs/coverage.pdf.

11. US Department of Labor. FAQS About Affordable Care Act Implementation (PART XII) [Internet]. 2014 [cited March 28, 2017]. Available from: http://www.dol.gov/ebsa/healthreform/.

12. American Lung Association. State Health Insurance Marketplace Plans: New Opportunities to Help Smokers Quit [Internet]. American Lung Association; 2015 [cited March 28, 2017]. Available from: http://www. lung.org/assets/documents/tobacco/state-health-insurance-opportunities.pdf.

13. Baker CL, Ferrufino CP, Bruno M, Kowal S. Estimated budget impact of adopting the affordable care act's required smoking cessation coverage on United States healthcare payers. Adv Ther. 2017;34(1):156-170.

14. Richard P, West K, Ku L. The return on investment of a Medicaid tobacco cessation program in Massachusetts. PLoS One. 2012;7(1):e29665.

15. Agency for Healthcare Research and Quality. Treating Tobacco Use and Dependence: 2008 Update [Internet]. [cited June 29, 2017]. Available from: https://www.ahrq.gov/professionals/clinicians-providers/ guidelines-recommendations/tobacco/index.html.

16. MEDPAC. A Data Book: Health Care Spending and the Medicare Program [Internet]. 2016 [cited June 29, 2017]. Available from: http:// www.medpac.gov/docs/default-source/data-book/june-2016-data-bookhealth-care-spending-and-the-medicare-program.pdf.

17. Coughlin TA, Long SK, Clemans-Cope L, Resnick D. What Difference Does Medicaid Make? Assessing Cost Effectiveness, Access, and Financial Protection under Medicaid for Low-Income Adults [Internet]. 2013 [cited June 29, 2017]. Available from: https://kaiserfamilyfoundation. files.wordpress.com/2013/05/8440-what-difference-does-medicaidmake2.pdf.

18. Ku L, Broaddus M. Public and private health insurance: stacking up the costs. Health Aff (Millwood). 2008;27(4):w318-w327.

19. Data on file. Pfizer Inc. New York N. OTC \& Retail Unit Sales from Nielsen xAOC, IQVIA National Prescription Audit ${ }^{\mathrm{TM}}$ (NPA) data (All Channels). 2017.

20. US Census Bureau. Distribution of US population by age and sex, 2017-2016. International Programs - Region Summary - U.S. Census Bureau [Internet]. [cited January 23, 2018]. Available from: https:// www.census.gov/data-tools/demo/idb/informationGateway.php.

21. Arias E, Heron M, Xu J. United States life tables, 2013. National Vital Statistics Reports, Vol 66, no 3. Hyattsville, MD: National Center for Health Statistics; 2017. Available from: https://www.cdc.gov/nchs/data/ nvsr/nvsr66/nvsr66_03.pdf.

22. Caraballo RS, Shafer PR, Patel D, Davis KC, McAfee TA. Quit methods used by US adult cigarette smokers, 2014-2016. Prev Chronic Dis. 2017; 14:160600.

23. Cahill K, Stevens S, Perera R, Lancaster T. Pharmacological interventions for smoking cessation: an overview and network meta-analysis. In: Cahill K, editor. Cochrane Database of Systematic Reviews [Internet]. Chichester, UK: John Wiley \& Sons, Ltd; 2013. Available from: http://www.ncbi.nlm.nih.gov/pubmed/23728690. Accessed March 28, 2017.

24. Wetter DW, Cofta-Gunn L, Fouladi RT, Cinciripini PM, Sui D, Gritz ER Late relapse/sustained abstinence among former smokers: a longitudinal study. Prev Med (Baltim). 2004;39(6):1156-1163. 
25. Maciosek MV, LaFrance AB, Dehmer SP, et al. Health benefits and cost-effectiveness of brief clinician tobacco counseling for youth and adults. Ann Fam Med. 2017;15(1):37-47.

26. Tobacco Use | Healthy People 2020 [Internet]. [cited October 16, 2017 ]. Available from: https:/www.healthypeople.gov/2020/topics-objectives/ topic/tobacco-use. Accessed October 16, 2017.

27. Dzau VJ, McClellan MB, McGinnis JM, et al. Vital directions for health and health care. JAMA. 2017;317(14):1461.
28. Mahmoudi M, Coleman CI, Sobieraj DM. Systematic review of the cost-effectiveness of varenicline vs. bupropion for smoking cessation. Int J Clin Pract. 2012;66(2):171-182.

29. Hawkins N, Sculpher M, Epstein D. Cost-effectiveness analysis of treatments for chronic disease: using $\mathrm{R}$ to incorporate time dependency of treatment response. Medical Decision Making. 2005;25(5): 511-519.

\section{Publish your work in this journal}

ClinicoEconomics and Outcomes Research is an international, peerreviewed open-access journal focusing on health technology assessment, pharmacoeconomics and outcomes research in the areas of diagnosis, medical devices, and clinical, surgical and pharmacological intervention. The economic impact of health policy and health systems
Submit your manuscript here: https://www.dovepress.com/clinicoeconomics-and-outcomes-research-journal organization also constitute important areas of coverage. The manuscript management system is completely online and includes a very quick and fair peer-review system, which is all easy to use. Visit http://www.dovepress.com/testimonials.php to read real quotes from published authors. 